\title{
Comparative study of immediate post placantal versus interval IUCD (CuT 380A Insertion)
}

\author{
Dolly Chawla $^{1}$, Rashmi Khatri ${ }^{2, *}$, Shylaja $T^{3}$, Menka Verma ${ }^{4}$ \\ ${ }^{1}$ Consultant and HOD, ${ }^{2}$ Specialist, ${ }^{3}$ DNB Resident, ${ }^{4}$ Senior Resident, Dept. of Obstetrics and Gynecology, Dr. Baba Saheb \\ Ambedkar Medical College and Hospital, New Delhi, India
}

*Corresponding Author:

Email: drrashmikhatri20144@gmail.com

\begin{abstract}
Introduction: Unintended pregnancy is still a major concern in India. It can be only prevented by effective contraceptive measures especially if it is used in postpartum period as it is highly vulnerable period to unintended pregnancy. The immediate postpartum period, after birth but before discharge from hospital is an important but underutilized time frame to initiate contraceptives specially long acting contraceptives like intrauterine contraceptive device. The study was conducted to evaluate the efficacy, side effects, continuation rates, and reasons for removal along with effects of expertise on complication rate between post partum IUCD, intra cesarean IUCD and interval IUCD insertion.

Materials and Methods: study was prospective randomized conducted on 300 women for one year. IUCD insertion was done in three groups; group A (post-placental), group B (intra cesarean), group C (interval IUCD). All the groups were evaluated and compared with respect to the efficacy, side effects, continuation rates, and reasons for removal along with effects of expertise on complication rate

Results: Most of women were of middle socioeconomic status and second gravida of age group 25-30 years of age. In all groups overall continuation rate after 6 weeks of insertion, 6 month and one year was $56.7 \%, 51.7 \%$ and $51.7 \%$ respectively. Complication rates are more after 6 weeks than 6 months and 1 year. Most common reason for removal was missing threads (16\%).Complications needing removal were less when inserted by consultants than residents.

Conclusions: We concluded that IUCD ( $\mathrm{Cu}$ T $380 \mathrm{~A})$ is an effective and safe reliable long term, reversible and convenient method of contraception which if properly implemented can help the unmet need of contraception to a greater extent even in postpartum period.
\end{abstract}

Keywords: Intrauterine contraceptive device, Postpartum, Interval, Intra cesarean, Complications.

\section{Introduction}

India faces huge challenges in terms of rapidly growing population. Approximately, $61 \%$ of births in India occur at intervals shorter than the recommended birth to birth interval of approximately 36 months, $78 \%$ of conceptions in India each year are unplanned and $25 \%$ are definitely unwanted. Currently $68 \%$ women are using contraception in developed world and it is $55 \%$ in the developing world. These statistics help explain why India accounts for more than $20 \%$ of global maternal and child deaths. Most of them are preventable through adequate nutrition, proper health care including access to family planning, the presence of a skilled birth attendant during delivery and emergency obstetric care. ${ }^{1,2}$

Intrauterine contraceptive device (IUCD) is an effective, long-lasting and reversible method of birth control with a cumulative pregnancy rate of less than 1 per 100 women within one first year of use. ${ }^{3,4}$ Since there is a large unmet need for family planning, the reasons being lack of awareness, fear of side effects, limited access and availability of services. There is need for a long lasting, safe, effective, acceptable contraceptive method in the post-partum period especially post partum IUCD. As institutional deliveries are increasing a lot which will make post-partum contraception more accessible to women, especially PPIUCD, which is a safe, long acting, reversible contraceptive method, with a very low failure rate, comparable to female sterilization and effective for family planning in India.

The present study was attempted to compare the efficacy of immediate post placental IUCD insertion with interval IUCD insertion. This study has also compared the adverse effects in post-partum and interval period in terms of perforation, abnormal bleeding, and pain abdomen. This study has also tried to understand the reason for the discontinuation or removal of the IUCD, so that the same problems may be addressed appropriately leading to increased continuation rates. Objectives of present study were.

1. To assess the acceptability and efficacy of $\mathrm{Cu} \mathrm{T}$ 380 A among the women attending Dr BSA Hospital.

2. To study complications in postpartum and interval period in terms of perforation, abnormal bleeding and pain abdomen.

3. To compare the expulsion rates.

4. To study the effects of expertise on complication rate.

5. To assess reasons for removal/discontinuation.

\section{Materials and Methods}

This was a prospective randomized study conducted at Dr Baba Saheb Ambedkar Hospital, New Delhi on 300 women attending Obstetrics \& 
Gynecology Department and family planning OPD. They were divided into three groups of 100 each. In Group A $(\mathrm{N}=100)$ IUCD was inserted after normal delivery (post placental insertion), In Group B $(\mathrm{N}=100)$ IUCD was inserted during cesarean section (intra cesarean insertion), In Group C ( $=100)$ where IUCD was inserted in interval period (interval period insertion). Women who attended ANC clinic, normal vaginal delivery, cesarean section, post natal clinic, family planning clinic were included in the study. Exclusion criteria for study were refusal by patient, chorioamnionitis, puerperal sepsis, unresolved post partum hemorrhage and premature rupture of membranes $>18$ hours. For interval period insertion, exclusion criteria was as per WHO MEC (medical eligibility criteria) criteria.

Study was started after getting ethical clearance from Dr Baba Saheb Ambedkar Hospital. Counselling was done to the women during their antenatal visits in the hospital, before undergoing a normal vaginal delivery for postpartum (PPIUCD) insertion, before cesarean delivery for intra cesarean insertion, at the time of discharge and in postnatal clinic for Interval period insertion. Informed consent was taken. Patients who desire a $\mathrm{Cu}$ T 380 A insertion were eligible for enrolment, irrespective of maternal age, risk factors and included in this study. All IUCDs were placed either by consultants, senior residents and DNB residents.

Post Placental Insertion: after delivery of the infant and placenta in normal vaginal delivery and after active management of third stage of labour, perineum was inspected for lacerations. Cervix was visualized using vaginal speculum, cervix and vagina was cleaned twice with sterile swabs, anterior lip of cervix was grasped with sponge holding forceps. IUCD with placental forceps was held in a sterile packet, forceps with IUCD was inserted through the cervix to lower uterine cavity, touching vagina was avoided and by placing the left hand on the sterile drape over the fundus of uterus, IUCD with forceps was advanced upward until it could be felt at fundus. Following contour of uterine cavity, forceps was opened and IUCD was released at fundus. By keeping the tongs open, forceps was swept to side walls of uterus and slowly removed. Uterus was stabilized until forceps are out; proper placement of IUCD was confirmed by nonvisibility of strings through cervix.

Intra Cesarean Insertion: after delivery of infant and placenta, IUCD placement was done into endometrial cavity through the uterine incision, IUCD was removed from its applicator and manually placed in the most proximal part of endometrial cavity and thread directed towards cervix.

Interval IUCD Insertion: was done through no touch technique. The cervix was swabbed with antiseptic. Gently the loaded inserter assembly was introduced through the cervical canal until the flange came in contact with the cervix. The plunger was held stationary and the insertion tube was withdrawn slightly so as to release the arms of the T. Gently the insertion tube was pushed upwards towards the top of the uterus until a slight resistance was felt, this ensured that the $T$ is closer to the fundus. The plunger was withdrawn while holding the insertion tube stationary and gently the insertion tube was withdrawn. $\mathrm{Cu} \mathrm{T}$ threads were cut so that they protrude only $2-3 \mathrm{~cm}$ into the vagina.

Prior to discharge from the hospital and after interval IUCD insertion patient was explained about rest, nutrition, hygiene and warning signs that warrant medical care i.e. bright red bleeding for which patient needs to change her pad $>6$ times/day, unusual abdominal or pelvic pain, unusual vaginal discharge, pain, fever and if IUCD had come out. Follow up visit were planned at after 6 weeks, 6 months and 1 year after insertion. Patients were followed in family planning OPD and telephonically at 6 weeks, 6 months and 1 year. On follow up visits detailed history and physical examination was done. Per speculum and per vaginal examination done to check strings, checked for signs of bleeding. Evaluated for expulsion by history, physical examination or USG.

Women explained to report back in case of missing thread or any warning sign or missed period and if wants to remove IUCD then asked for reasons and asked for acceptability and satisfaction.

Outcomes

Present study analysed the following upto 1 year of follow up

1. Efficacy

2. Expulsion rates

3. Complication rates like pain abdomen, bleeding $\mathrm{p} / \mathrm{v}$

4. Removal rates and reasons of removal

5. Effects of expertise on complication rate

Statistical Analysis: It was done by using statistical software spss version 13. For quantitative data student ' $t$ ' test/ non parametric/ Wilcoxon Mann Whitney rank sum test were used and for qualitative data Chi square/Fischer's exact test were used. $\mathrm{P}$ value $<0.05$ was the cut off point for statistical significance.

\section{Results}

Age: Majority of the patients belonged to 25 to 30 years of age in all the three groups $(50.6 \%)$. Mean age of enrolment in all the three groups was comparable and not statistically significant ( $\mathrm{p}$ value $=0.198$ ).

Socio Economic Status: Among all the three groups 52 $(17.3 \%)$ subjects pertain to low social economic status and $248(82.7 \%)$ subjects belong to middle social economic status. This indicates that majority of the person were from middle social economic status and the difference was not significant ( $p$ value of 0.850 )

Parity: Second para women constituted the maximum percentage composition in all 3 groups. There was statistical significant difference between the groups with regard to parity $(\mathrm{p}<0.001)$. 
IUCD Insertion by Various Experts: Results revealed that among the 300 subjects, IUCD was inserted by consultants in $59(19.7 \%)$ subjects, by senior residents in $180(60 \%)$ subjects and by postgraduates DNB students in $61(20.3 \%)$ subjects. Majorities of IUCD was inserted by the senior residents and IUCD insertion done by Consultants and DNB residents was almost equal.

Table 1: Continuation and removal at 6 weeks follow up

\begin{tabular}{|c|c|c|c|c|c|c|c|}
\hline \multicolumn{7}{|l|}{ Crosstab } & \multirow{3}{*}{ P-value } \\
\hline & & & \multicolumn{3}{|c|}{ Time of insertion } & \multirow[t]{2}{*}{ Total } & \\
\hline & & & Interval & Post cesarean & Post delivery & & \\
\hline \multirow{6}{*}{$\begin{array}{c}\text { Follow up at } \\
6 \\
\text { Weeks }\end{array}$} & \multirow[t]{2}{*}{ Continued } & Count & 62 & 48 & 60 & 170 & 0.081 \\
\hline & & $\%$ of Total & $20.7 \%$ & $16.0 \%$ & $20.0 \%$ & $56.7 \%$ & \\
\hline & \multirow[b]{2}{*}{ Removed } & Count & 32 & 40 & 26 & 98 & \\
\hline & & $\%$ of Total & $10.7 \%$ & $13.3 \%$ & $8.7 \%$ & $32.7 \%$ & \\
\hline & \multirow{2}{*}{$\begin{array}{l}\text { Could not } \\
\text { follow up }\end{array}$} & Count & 6 & 12 & 14 & 32 & \\
\hline & & $\%$ of Total & $2.0 \%$ & $4.0 \%$ & $4.7 \%$ & $10.7 \%$ & \\
\hline \multirow{2}{*}{\multicolumn{2}{|c|}{ Total }} & Count & 100 & 100 & 100 & 300 & \\
\hline & & $\%$ of Total & $33.3 \%$ & $33.3 \%$ & $33.3 \%$ & $100.0 \%$ & \\
\hline
\end{tabular}

Table 1 shows that out of 300 patients, 98 (32.7\%) patients removed CU T. Among which $40 \%$ belonged to intra cesarean $>32 \%$ to interval $>26 \%$ to post delivery. 32(10.7\%) could not follow up (p value not significant)

Table 2 complaints at 6 weeks

\begin{tabular}{|c|c|c|c|c|c|c|c|}
\hline \multicolumn{8}{|l|}{ Crosstab } \\
\hline & & & & Time of inser & & Total & P-value \\
\hline & & & Interval & Post cesarean & Post delivery & & \\
\hline \multirow{10}{*}{$\begin{array}{l}\text { Complaint at } \\
6 \text { weeks }\end{array}$} & \multirow[t]{2}{*}{ Excess BPV } & Count & 17 & 12 & 11 & 40 & 0.053 \\
\hline & & $\%$ of Total & $5.7 \%$ & $4.0 \%$ & $3.7 \%$ & $13.3 \%$ & \\
\hline & \multirow[t]{2}{*}{ Missing thread } & Count & 4 & 1 & 4 & 9 & \\
\hline & & $\%$ of Total & $1.3 \%$ & $0.3 \%$ & $1.3 \%$ & $3.0 \%$ & \\
\hline & \multirow[t]{2}{*}{ No complaint } & Count & 18 & 12 & 29 & 59 & \\
\hline & & $\%$ of Total & $6.0 \%$ & $4.0 \%$ & $9.7 \%$ & $19.7 \%$ & \\
\hline & \multirow[t]{2}{*}{ Not applicable } & Count & 38 & 52 & 40 & 130 & \\
\hline & & $\%$ of Total & $12.7 \%$ & $17.3 \%$ & $13.3 \%$ & $43.3 \%$ & \\
\hline & \multirow[t]{2}{*}{ Pain Abdomen } & Count & 23 & 23 & 16 & 62 & \\
\hline & & $\%$ of Total & $7.7 \%$ & $7.7 \%$ & $5.3 \%$ & $20.7 \%$ & \\
\hline \multirow{2}{*}{\multicolumn{2}{|c|}{ Total }} & Count & 100 & 100 & 100 & 300 & \\
\hline & & $\%$ of Total & $33.3 \%$ & $33.3 \%$ & $33.3 \%$ & $100.0 \%$ & \\
\hline
\end{tabular}

Table 2 shows that among 300 subjects, 59 (19.7\%) subjects have not reported any complaint, 62 (20.7\%) subjects reported pain abdomen, 9 (3\%) subjects reported missing thread, 40 (13.3\%) reported excess bleeding. Complaints were almost comparable in all groups and statistically not significant.

In follow up after 6 months of insertion of IUCD it was found that among 170 subjects, 15 (5\%) subjects got their IUCD removed while155subjects continued. Out of 155 , one subject $(0.3 \%)$ had pain abdomen, excess bleeding per vagina was found in one $(0.3 \%)$ rest 153 patients had no complaints. Complaints were almost same in all the three groups at 6 months. IUCD was continued in all 155 (51.7\%) subjects at one year. No Complaints noted after 1 year of insertion when compared to complaints in 6 months and 6 weeks of insertion.

Table 3 Cause of removal*time of insertion

\begin{tabular}{|c|c|c|c|c|c|c|c|}
\hline \multicolumn{8}{|l|}{ Crosstab } \\
\hline & & & & Time of inser & & Total & P-value \\
\hline & & & Interval & Post cesarean & Post delivery & & \\
\hline \multirow{9}{*}{$\begin{array}{l}\text { Cause of } \\
\text { Removal }\end{array}$} & \multirow[t]{2}{*}{ Excess BPV } & Count & 9 & 15 & 10 & 34 & 0.001 \\
\hline & & $\%$ of Total & $3.0 \%$ & $5.0 \%$ & $3.3 \%$ & $11.3 \%$ & \\
\hline & \multirow[t]{2}{*}{ Missing threads } & Count & 7 & 19 & 22 & 48 & \\
\hline & & $\%$ of Total & $2.3 \%$ & $6.3 \%$ & $7.3 \%$ & $16.0 \%$ & \\
\hline & \multirow[t]{2}{*}{ No Removal } & Count & 61 & 46 & 48 & 155 & \\
\hline & & $\%$ of Total & $20.3 \%$ & $15.3 \%$ & $16.0 \%$ & $51.7 \%$ & \\
\hline & \multirow[t]{2}{*}{ Not Applicable } & Count & 6 & 12 & 14 & 32 & \\
\hline & & $\%$ of Total & $2.0 \%$ & $4.0 \%$ & $4.7 \%$ & $10.7 \%$ & \\
\hline & Pregnant & Count & 0 & 1 & 1 & 2 & \\
\hline
\end{tabular}




\begin{tabular}{|c|c|c|c|c|c|}
\hline & $\%$ of Total & $0.0 \%$ & $0.3 \%$ & $0.3 \%$ & $0.7 \%$ \\
\hline \multirow[t]{2}{*}{ Reinserted } & Count & 0 & 1 & 0 & 1 \\
\hline & $\%$ of Total & $0.0 \%$ & $0.3 \%$ & $0.0 \%$ & $0.3 \%$ \\
\hline \multirow[t]{2}{*}{ To conceive } & Count & 8 & 0 & 0 & 8 \\
\hline & $\%$ of Total & $2.7 \%$ & $0.0 \%$ & $0.0 \%$ & $2.7 \%$ \\
\hline \multirow[t]{2}{*}{ Tubal ligation } & Count & 9 & 6 & 5 & 20 \\
\hline & $\%$ of Total & $3.0 \%$ & $2.0 \%$ & $1.7 \%$ & $6.7 \%$ \\
\hline \multirow[t]{2}{*}{ Total } & Count & 100 & 100 & 100 & 300 \\
\hline & $\%$ of Total & $33.3 \%$ & $33.3 \%$ & $33.3 \%$ & $100.0 \%$ \\
\hline
\end{tabular}

Main complications were excessive BPV 34(11.3\%, missing threads 48(16\%), desire to conceive and tubal ligation. Commonest cause of IUCD removal in postpartum period was missing thread whereas excess BPV and desire for tubal ligation in interval group. Most common reason in all groups being missing thread (48patients 16\% of total) with statistically being significant.

Table 4: Effect of expertise on complication rate at 6 weeks

\begin{tabular}{|c|c|c|c|c|c|c|c|}
\hline \multicolumn{7}{|l|}{ Crosstab } & \multirow{3}{*}{ P-value } \\
\hline & & & \multicolumn{3}{|c|}{ Insertion done by } & \multirow[t]{2}{*}{ Total } & \\
\hline & & & Consultant & SR & DNB & & \\
\hline \multirow{10}{*}{$\begin{array}{l}\text { Complaint } \\
\text { at } 6 \text { weeks }\end{array}$} & \multirow[t]{2}{*}{ Excess BPV } & Count & 7 & 28 & 5 & 40 & $<0.001$ \\
\hline & & $\%$ of Total & $2.3 \%$ & $9.3 \%$ & $1.7 \%$ & $13.3 \%$ & \\
\hline & \multirow{2}{*}{$\begin{array}{c}\text { Missing } \\
\text { thread }\end{array}$} & Count & 3 & 4 & 2 & 9 & \\
\hline & & $\%$ of Total & $1.0 \%$ & $1.3 \%$ & $0.7 \%$ & $3.0 \%$ & \\
\hline & \multirow{2}{*}{$\begin{array}{c}\text { No } \\
\text { Complaint } \\
\end{array}$} & Count & 25 & 26 & 8 & 59 & \\
\hline & & $\%$ of Total & $8.3 \%$ & $8.7 \%$ & $2.7 \%$ & $19.7 \%$ & \\
\hline & \multirow{2}{*}{$\begin{array}{c}\text { Not } \\
\text { Applicable }\end{array}$} & Count & 6 & 91 & 33 & 130 & \\
\hline & & $\%$ of Total & $2.0 \%$ & $30.3 \%$ & $11.0 \%$ & $43.3 \%$ & \\
\hline & \multirow{2}{*}{$\begin{array}{c}\text { Pain } \\
\text { Abdomen }\end{array}$} & Count & 18 & 31 & 13 & 62 & \\
\hline & & $\%$ of Total & $6.0 \%$ & $10.3 \%$ & $4.3 \%$ & $20.7 \%$ & \\
\hline \multirow[t]{2}{*}{ Total } & \multicolumn{2}{|c|}{ Count } & 59 & 180 & 61 & 300 & \\
\hline & \multicolumn{2}{|c|}{$\%$ of Total } & $19.7 \%$ & $60.0 \%$ & $20.3 \%$ & $100.0 \%$ & \\
\hline
\end{tabular}

Complication rate was less when inserted by consultants as compared to residents at 6 weeks 40 patients had BPV, out of which 28 were inserted by senior resident out of 62 patients with pain in abdomen, 31 were inserted by senior residents. This was highly significant ( $\mathrm{p}$ value $<0.01$ ).

Table 5: causes of removal when insertion done by various experts

\begin{tabular}{|c|c|c|c|c|c|c|c|}
\hline \multicolumn{7}{|l|}{ Crosstab } & \multirow{3}{*}{ P-value } \\
\hline & & & \multicolumn{3}{|c|}{ Insertion done by } & \multirow[t]{2}{*}{ Total } & \\
\hline & & & Consultant & SR & DNB & & \\
\hline \multirow{16}{*}{$\begin{array}{l}\text { Cause of } \\
\text { removal }\end{array}$} & \multirow[t]{2}{*}{ Excess BPV } & Count & 3 & 20 & 11 & 34 & $<0.001$ \\
\hline & & $\%$ of Total & $1.0 \%$ & $6.7 \%$ & $3.7 \%$ & $11.3 \%$ & \\
\hline & \multirow[t]{2}{*}{ Missing threads } & Count & 2 & 31 & 15 & 48 & \\
\hline & & $\%$ of Total & $0.7 \%$ & $10.3 \%$ & $5.0 \%$ & $16.0 \%$ & \\
\hline & \multirow[t]{2}{*}{ No Removal } & Count & 53 & 80 & 22 & 155 & \\
\hline & & $\%$ of Total & $7.7 \%$ & $26.7 \%$ & $17.3 \%$ & $51.7 \%$ & \\
\hline & \multirow[t]{2}{*}{ Pain abdomen } & Count & 1 & 27 & 4 & 32 & \\
\hline & & $\%$ of Total & $0.3 \%$ & $9.0 \%$ & $1.3 \%$ & $10.7 \%$ & \\
\hline & \multirow[t]{2}{*}{ Pregnant } & Count & 0 & 2 & 0 & 2 & \\
\hline & & $\%$ of Total & $0.0 \%$ & $0.7 \%$ & $0.0 \%$ & $0.7 \%$ & \\
\hline & \multirow[t]{2}{*}{ Reinserted } & Count & 0 & 1 & 0 & 1 & \\
\hline & & $\%$ of Total & $0.0 \%$ & $0.3 \%$ & $0.0 \%$ & $0.3 \%$ & \\
\hline & \multirow[t]{2}{*}{ To conceive } & Count & 0 & 6 & 2 & 8 & \\
\hline & & $\%$ of Total & $0.0 \%$ & $2.0 \%$ & $0.7 \%$ & $2.7 \%$ & \\
\hline & \multirow[t]{2}{*}{ Tubal ligation } & Count & 0 & 13 & 7 & 20 & \\
\hline & & $\%$ of Total & $0.0 \%$ & $4.3 \%$ & $2.3 \%$ & $6.7 \%$ & \\
\hline \multirow{2}{*}{\multicolumn{2}{|c|}{ Total }} & Count & 59 & 180 & 61 & 300 & \\
\hline & & $\%$ of Total & $19.7 \%$ & $60.0 \%$ & $20.3 \%$ & $100.0 \%$ & \\
\hline
\end{tabular}

Table 5 showed complications like pain abdomen, missing threads, excess BPV, removal rate are less when inserted by consultants the statistical value is significant ( $\mathrm{p}$ value $<0.001$ ) 


\section{Discussion}

Despite the availability of safe and effective forms of contraception and increasing contraceptive use, societies of developing countries encounter unacceptably high rates of unintended and unwanted pregnancies which contribute to population growth. Our study was undertaken to evaluate the efficacy, side effects, continuation rates, and reasons for removal along with effects of expertise on complication rate between post partum IUCD, intra cesarean IUCD and interval IUCD insertion.

Mean age of distribution in this study for IUCD insertion was 25-30 yrs. Mean age of participating women was 25.94 years which was comparable to population study by Xu et al (24.55yrs+/- $3.1 \mathrm{yrs})$. In total 300 subjects, insertion of IUCD was in P1 (24.7\%), P2 (46.3\%), P3 (19.3\%), P4 (4\%), P5(2.3\%), P7(0.3\%). IUCD insertion was accepted more by $2^{\text {nd }}$ gravida $(46.3 \%)$ followed by 3rd gravida $(19.3 \%)$ than primi (24.7\%), this finding is supported to the study by Grimes et al. where they found higher acceptance in multiparous clients. ${ }^{5,6}$

Socio economically our population predominantly belonged to lower and middle socio economic class in all 3 groups. This could possibly explain the fact that the place of the study is a developing country and set up was a tertiary government hospital with cost free treatment to all, accessible to all strata of population.

Continuation rates in the study were in interval $(60 \%)>$ post partum $(52 \%)>$ intra cesarean $(46 \%)$ insertion. Despite complications, after 6 weeks of insertion continuation rate was $56.7 \%$, after 6 months $51.7 \%$ and after 1 year $51.7 \%$.

Complication rates in the study were in intra cesarean (missing threads 17\%)> post partum (pain abdomen 14\%) > interval (pain abdomen 12\%). Complication rates are more after follow up after 6 weeks than after 6 months and 1 year of follow up.

Data of the follow up after IUCD insertion after 6 weeks, 6 months and 1 year has shown that IUCD $(\mathrm{Cu}$ T 380 A) has a high complication rate after 6 weeks of insertion (13.3\%) when compared to complications at 6 months and 1 year of insertion. The complications rates are high in intra cesarean group than in postpartum and interval group. No case of perforation is noted in our study.

In our study, reasons for removal were missing threads $(16 \%)>$ excess BPV $(11.7 \%)>$ tubal ligation $(6.7 \%)>$ to conceive $(3.3 \%)>$ pregnancy with $\mathrm{Cu} \mathrm{T}$ $(0.7 \%)$ and this data is supported by the study by Lara Ricalde research team. ${ }^{7}$

Nathalie Kapp research group conclude that the removal rate of intra uterine device due to bleeding, pain and other medical reasons were same for participants after vaginal delivery v/s intra-caesarean and it was found to be $13.5 \%$ and $11.3 \%$ respectively. Expulsion rates were $17.1 \pm 4.2 \%$ for vaginal insertion $\mathrm{v} / \mathrm{s} 4.3 \pm 2.9 \%$ for intra-caesarean insertion. ${ }^{8}$
The study data collected after follow up shows the continuation rates are $56.7 \%$ after 6 weeks of insertion, $51.7 \%$ after 6 months and $51.7 \%$ after 1 year of insertion. Our research findings support the results of the study carried out by celen research team in $2011 .^{9}$

Farouk Fikry research team concluded that continuation rates were $82.90 \%$ for post-placental insertion of intra uterine device, $75 \%$ for postpartum insertion of intra uterine device and $95.50 \%$ for intra caesarean group and cumulative continuation rate was $84.70 \%$ for the intra uterine device. ${ }^{10}$

Manju Shukla et al (2012) concluded that although the expulsion rate for immediate post-partum insertion was higher than for interval insertion, the benefits of providing highly effective contraception immediately after delivery outweigh this disadvantage, particularly in country where women have limited access to medical care $^{11}$.

Teal SB research group completed a cohort study of 136 young mothers participants from an adolescent pregnancy/postpartum programme and concluded that twelve-month follow ups revealed the continuation of the intra uterine device was $55 \%$, the most common reasons being expulsion (14.2\%), pain (12.2\%), bleeding $(7.4 \%)$, pregnancy desire $(6.8 \%)$ and pregnancy $(4.7 \%) .^{12}$

A study done at Safdarjung hospital in Delhi had concluded that at the end of one year, there were 16 expulsions, 21 removals, and 2 pregnancies with gross cumulative expulsion, removal, failure and continuation rates of $5.33 \%, 7 \%, 0.67 \%$ and $91 \%$, respectively. ${ }^{13}$

Data on complication rate after expertise insertion has shown that complications incidence are less when inserted by consultants $(1.7 \%)$ than when inserted by SRS (16.7\%) and DNBS (18.7\%). Removal rate when insertion done by consultants was less than when inserted by SRS and DNB students.

This data emphasizes that a better training programme and further studies should be done which can make trained personnel available for insertion, which would further lead to better continuation rate.

\section{Conclusion}

We concluded that IUCD ( $\mathrm{Cu}$ T $380 \mathrm{~A})$ is an effective and safe reliable long term, reversible and convenient method of contraception which if properly implemented can help the unmet need of contraception to a greater extent. Postpartum IUCD insertion is an opportunity not to be missed in developing countries like ours where delivery may be the only time when a healthy woman comes into contact with health care providers and the chances of returning for contraceptive advice are uncertain. Continuation rate is more and complication rate is less with interval IUCD insertion compared to post partum IUCD and intra cesarean IUCD insertion. PPIUCD is beneficial in providing immediate contraceptive benefit when women are present in the health facility only. The PPIUCD $(\mathrm{Cu} \mathrm{T}$ 
380) had high retention rate. The expulsion rate was not very high and it can be reduced with practice. With the high level of acceptance despite low levels of awareness, the government needs to develop strategies to increase public awareness of the PPIUCD.

\section{References}

1. K. Park's Text book of Preventive and Social Medicine, $21^{\text {st }}$ edition, chapter 10 , table 13,515 .

2. Conde-Agudelo, A, Belizan, JM, et al Maternal morbidity and mortality associated with interpregnancy interval: cross sectional study. Br Med J, 2000;321(7271):1255-9.

3. K, Huber D. Postpartum IUDs: Keys for success. Contraception 1992,45:351-361.

4. World Health Organization. Improving access to quality care in family Planning. Medical eligibility criteria for contraceptive use. Third edition, 2004. WHO;Geneva.

5. Xu j, Yang $\mathrm{X}$ et al Comparison between two techniques used in immediate postplacental insertion of TCu 380A intrauterine device: 36-month follow up. Contraception 1999;10(3):156-62.

6. Grimes D, Schulz K, van Vliet H, et al immediate postpartum insertion of intrauterine devices, the Cochrane library, 2005, Issue 3, 7.

7. Lara Ricalde R, Menocal Tobías G, Ramos Pérez C, Velázquez Ramírez N. Random comparative study between intrauterine device Multiload Cu375 and CuT $380 \mathrm{~A}$ inserted in the postpartum period. Ginecol Obstet Mex, 2006 Jun;74(6):306-11.

8. Nathalie Kapp, Intrauterine device insertion during the postpartum period: a systematic review. Contraception 80 (2009) 327-336.

9. Celen S, Sucak A, Yildiz Y, Danisman N. Immediate post-placental insertion of an intrauterine contraceptive device during cesarean section. Contraception 84 (2011)240-243.

10. Farouk Fikry, Amr Nadim. Postpartum intratuerine device contraception - An experience from Egypt. Contraception, 2010 306-312.

11. Manju Shukla, Sabuhi Qureshi, Chandrawati. Postplacental intrauterine device insertion - A five year experience at a tertiary care centre in north India.

12. Teal SB, Sheeder J. IUD use in adolescent mothers: retention, failure and reasons for discontinuation. Contraception, 2012 Mar;85(3):270-4.

13. Sunita Singal, clinical outcome (safety, efficacy, expulsion and continuation rates) of postplacental Copper $\mathrm{T} 380 \mathrm{~A}$ insertion in primiparous women undergoing caesarean section. J Clin Diagn Res. 2014

Sep;8(9):OC01-OC04. 